\title{
SPONTANEOUS SPLENIC RUPTURE IN TWO PATIENTS WITH HEMATOLOGIC MALIGNANCY
}

\author{
Tomas Szotkowski ${ }^{\mathrm{a}}$, Romana Szotkowska ${ }^{\mathrm{a}}$, Zuzana Pikalova ${ }^{\mathrm{a}}$, Tomas Tichy ${ }^{\mathrm{b}}$, Patrik Flodr ${ }^{\mathrm{b}}$, \\ Martin Tichyb, Dana Houserkova ${ }^{\mathrm{c}}$, Vladimir Benysek ${ }^{\mathrm{c}}$, Nora Zlamalova ${ }^{\mathrm{d}}$, Vaclav Ruzicka ${ }^{\mathrm{d}}$, \\ Karel Indrak ${ }^{\mathrm{a}}$
}

\author{
${ }^{a}$ Department of Hemato-oncology, Faculty of Medicine and Dentistry, Palacky University, University Hospital Olomouc, \\ Czech Republic \\ ${ }^{b}$ Department of Pathology, Faculty of Medicine and Dentistry, Palacky University, University Hospital Olomouc \\ c Department of Radiology, Faculty of Medicine and Dentistry, Palacky University, University Hospital Olomouc \\ ${ }^{d} I^{\text {st }}$ Department of Surgery, Faculty of Medicine and Dentistry, Palacky University, University Hospital Olomouc \\ e-mail:tomast123@seznam.cz
}

Received: March 23, 2007; Accepted (with revision): May 10, 2007

Key words: Spontaneous splenic rupture/Hairy cell leukaemia/Diffuse large B-cell lymphoma/Sudden stomach pain/Hypovolemic shock/Hematologic malignancy

Background: Spontaneous splenic rupture (SSR) is a very rare complication described in several hundred patients, mainly as case reports. It is defined as a splenic rupture without antecedent injury. The authors of the present paper describe the only two SSR cases diagnosed at the Hemato-oncology department, coincidentally in one year.

Patients: The first patient was admitted to hospital because of planned chemotherapy for relapsed hairy cell leukemia. The second was directed to the Hemato-oncology outpatient department because of anemia and painful splenomegaly diagnosed by a physician. The diagnose of hematologic malignancy (diffuse large B-cell lymphoma) was determined subsequently on the basis of histological examination of the spleen.

Conclusion: It is necessary to consider SSR not only in patients with known diagnosis of malignant disease but in the patients with negative anamnesis, too. The aim of the paper is to draw attention to the existence of this complication.

\section{INTRODUCTION}

Spontaneous splenic rupture (SSR) is a very rare complication described in several hundred patients, mainly as case reports. It is defined as a splenic rupture without external cause (antecedent injury). Some authors distinguish between SSR with a known cause (known primary disease) and idiopathic SSR ${ }^{1}$.

SSR generally clinically manifests as a sudden stomach pain and hypovolemic shock. It is a life-threatening complication. The aim of this paper is to draw attention to the existence, clinical course, differential diagnosis, etiology and treatment options for SSR.

\section{CASE REPORT 1}

A 39-year-old man was admitted to the Hemato-oncology department for planned chemotherapy after the first relapse of hairy cell leukemia (HCL). The diagnosis of hematologic malignancy was determined in 2002. After one cycle of cladribin (2-chlorodeoxyadenosin) a complete hematologic remission was achieved. The remission lasted for 3 years.
The patient had no subjective complaints at the time of admission. Objective examination showed mild splenomegaly. No other pathology was found. Laboratory examination revealed pancytopenia - anemia $8.9 \mathrm{~g} / \mathrm{dl}$, mean cell volume (MCV) $101.8 \mathrm{fl}$, hematocrit 0.28 , leukopenia $0.8 \times 10^{9} / 1$, thrombocytopenia $28 \times 10^{9} / 1$.

The same day in the evening, after supper, the patient started to complain of nausea and a convulsive stomach pain. These symptoms were followed by brief unconsciousness. Hypotension (blood pressure (BP) $=90 / 60 \mathrm{~mm} \mathrm{Hg}$ ) and tachycardia (heart rate $(\mathrm{HR})=110 / \mathrm{min}$ ) were then found. We excluded coronary lesion as a cause of shock and neurological examination revealed no pathology either. Complete blood counts (CBC) showed profound anemia (hemoglobin $(\mathrm{Hb}) 6.5 \mathrm{~g} / \mathrm{dl}$ ) otherwise decline of $\mathrm{Hb} 2.4 \mathrm{~g} / \mathrm{dl}$ over the previous 12 hours. Other laboratory results were: leukocyte count $1.6 \times 10^{9} / 1$, platelet count $20 \times 10^{9} / 1$. Coagulation (PT, aPTT, TT, FBG) the results were within the normal range.

The intensive supportive treatment including erythrocyte and platelet substitution was started. The surgical consultant recommended urgent gastrofibroscopy (normal result) and CT scan of abdomen. The radiologist described large splenomegaly $250 \times 210 \times 120 \mathrm{~mm}$ with central 
inhomogeneities and liquid located underneath the spleen and in the paracolic space on the left. He expressed a suspicion of intraabdominal bleeding. Despite the intensive conservative treatment including 2 transfusion units of erythrocytes and 2 transfusion units of platelets the abdominal pain continued, the hypotension deteriorated and anemia worsened $(\mathrm{Hb} 5.1 \mathrm{~g} / \mathrm{dl})$.

Laparotomy was indicated approximately 8 hours after symptoms initiation. The splenic rupture and hemoperitoneum were revealed and splenectomy was performed. The surgery was managed without complications. Rapid improvement in the patient's health followed. Blood counts improved. Hb level was $10.2 \mathrm{~g} / \mathrm{dl} 7$ days after splenectomy, leukocyte count was $3.5 \times 10^{9} / 1$ and platelet count was $178 \times 10^{9} / 1$ at the same time. Histological examination of the spleen confirmed diffuse hairy cell infiltration (Fig. 1, 2). The patient has been followed for 20 months after splenectomy, without complication.

\section{CASE REPORT 2}

A 60-year-old man was directed to the outpatient clinic of the Hemato-oncology department for anemia and painful splenomegaly diagnosed by a physician in June 2006. The splenomegaly ( $180 \mathrm{~mm}$ ) and suspicion of subphrenic hematoma were found during abdominal ultrasonography in a local clinic. CBC analysis revealed anemia $10.6 \mathrm{~g} / \mathrm{dl}$ 3 days before visiting the Hemato-oncology department. The patient also complained of dyspnoea, marked weakness, paroxysmal sweat and subfebriles. Despite repeated targeted questions he denied any anticipated injury.

Objective examination showed marked skin pallor, hypotension ( $\mathrm{BP}=100 / 70 \mathrm{~mm} \mathrm{Hg}$ ) and tachycardia $(\mathrm{HR}=100 / \mathrm{min})$. The abdomen was difficult to examine,

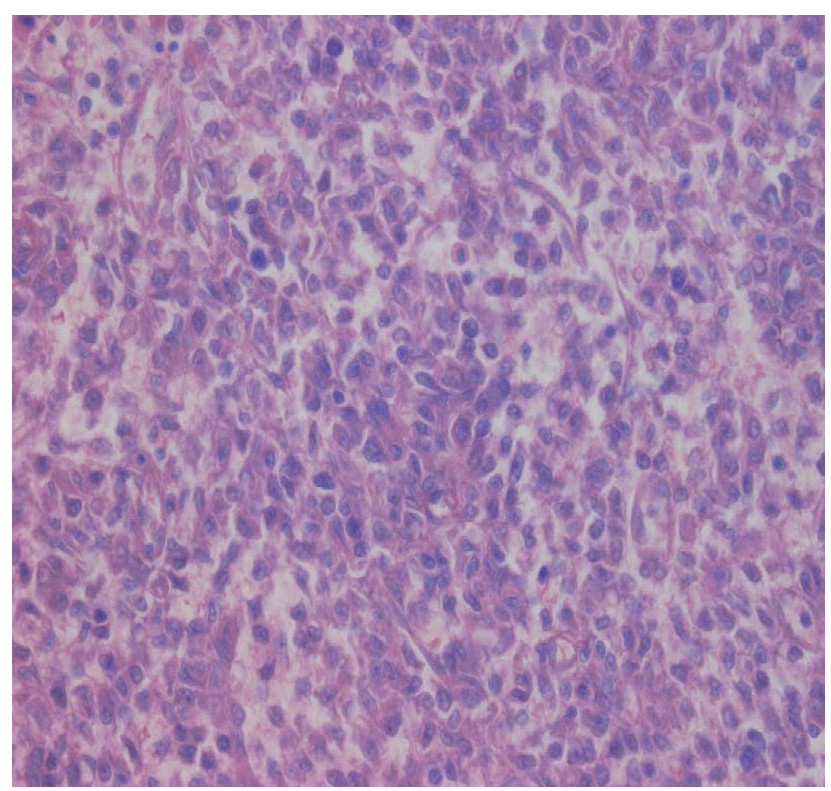

Fig. 1. Spleen - hairy cell leukemia (Giemsa 400×). The spleen showed the typical red pulp expansion of HCL. with diffuse palpation pain and painful splenomegaly. Laboratory examination produced these findings: CBC: $\mathrm{Hb} 8.5 \mathrm{~g} / \mathrm{dl}$, hematocrit 0.26, MCV $90.9 \mathrm{fl}$, leukocyte count $7.87 \times 10^{9} / 1$, platelet count $102 \times 10^{9} / 1$, coagulation: PT 19.06 s, INR 1.66, aPTT 24.1 s, TT 13.3 s, fibrinogen $2.13 \mathrm{~g} / 1$, antithrombin III $67 \%$.

Due to a suspicion of intra-abdominal bleeding the patient was transferred to surgery. An abdominal CT scan revealed marked splenomegaly $(190 \mathrm{~mm})$ with native hypodense focuses and inhomogenous structure. Three conspicuous hyperdense focuses up to $12 \mathrm{~mm}$ suspected of having a hemorrhagic etiology were identified after contrast medium administration (Figs. 3, 4). Laparotomy was performed because of progressive anemia and clinical signs of developing hypovolemic shock. Hemoperitoneum and splenic rupture were found and splenectomy was performed. Histologic and immunohistochemic examination revealed splenic infiltration with diffuse large Bcell lymphoma (Fig. 5). The malignancy was generalized with peritoneal infiltration and malignant ascites, thus intensive immunochemotherapy (chemotherapy combined with monoclonal antibody anti-CD20) was recommended. Patient also underwent an autologous stem cell transplantation. Complete remission of the lymphoma was achieved.

\section{DISCUSSION}

Spontaneous splenic rupture is a rare, but potentially life-threatening complication. Most papers related to SSR are case reports because of its low occurrence. The most comprehensive study describing a group of 41 patients was published in 2003 by Görg et al. ${ }^{2}$

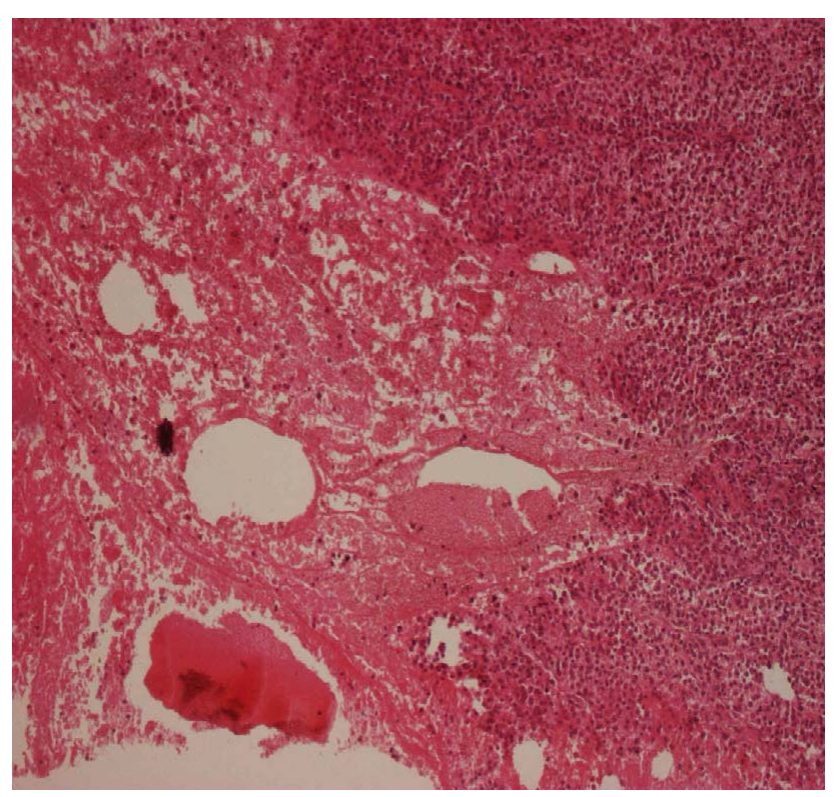

Fig. 2. Spleen - hairy cell leukemia (HE 100×). 


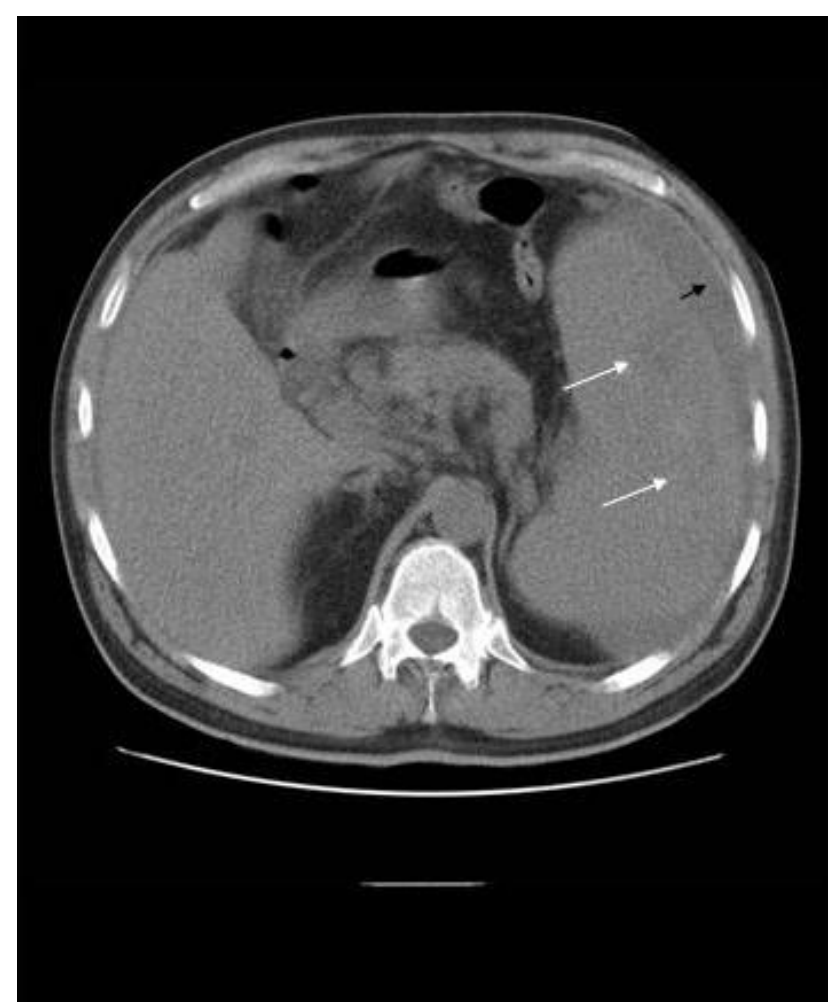

Fig. 3. Native CT scan of abdomen. Free liquid around spleen - hemoperitoneum (black arrow). Marked splenomegaly - $190 \mathrm{~mm}$. Inhomogenous structure of parenchyma with fuzzy edged hypodensic lesions in inferior part of the spleen, that are indicative of small infarction focuses (white arrows).

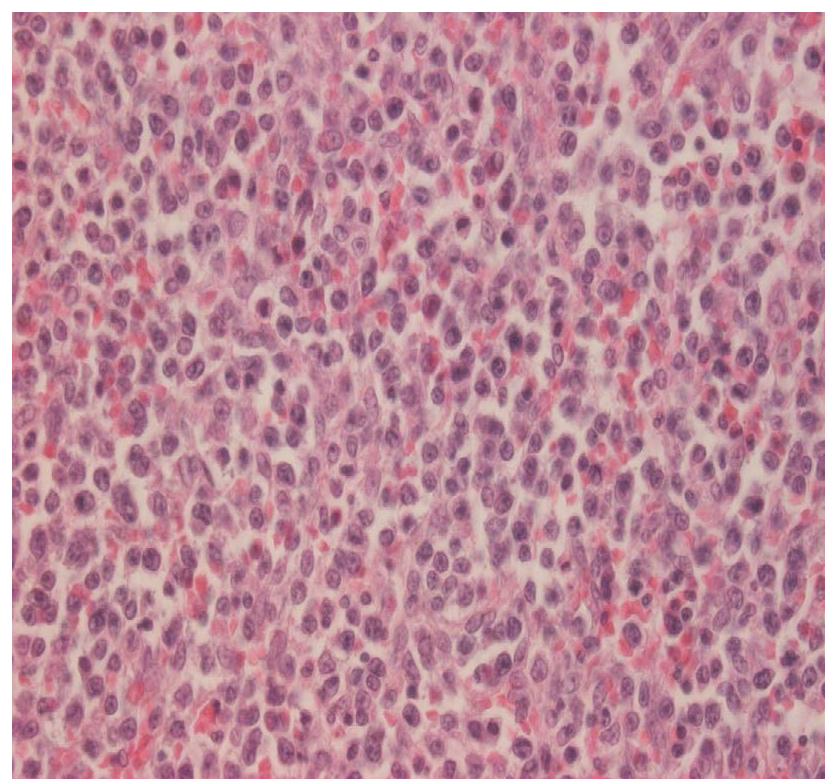

Fig. 5. Spleen - diffuse large B-cell lymphoma (Giemsa $400 \times)$.

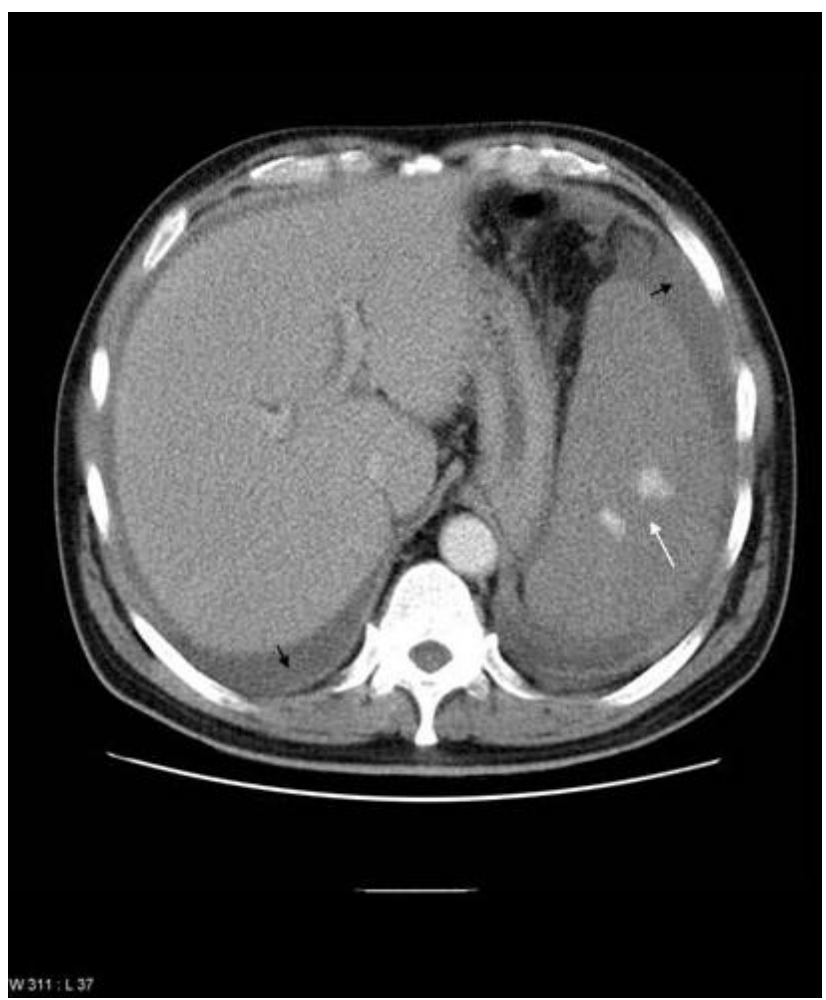

Fig. 4. Hemoperitoneum - around liver and spleen (black arrows). There are visible considerably hyperdense small lesions in the central part of the spleen after intravenous contrast medium administration, as a sign of acute intrasplenic bleeding (white arrow).

The incidence of SSR is usually not published. The authors of the present paper describe the only two SSR cases diagnosed at the Hemato-oncology department, coincidentally in one year.

SSR is usually a complication of disorders that cause congestion or pathologic infiltration of spleen. Tumours ${ }^{3-5}$, hematopoietic system disorders ${ }^{3,5-7}$ and infections ${ }^{8-10}$ should be mentioned here. It can also be a complication of bleeding disorders and anticoagulant therapy ${ }^{11,12}$, splenic infarctions, autoimmune disorders, amyloidosis, portal hypertension, splenic pseudocystis in chronic pancreatitis ${ }^{13}$, etc. Filgrastim stimulation in voluntary hematopoietic cells donor can occasionally be complicated by SSR ${ }^{14,15}$. Sometimes the search for the cause fails.

The incidence of SSR is unknown. We do not know the relative proportion of patients with this complication in groups defined by primary disease. The great majority (approximately $80 \%$ ) of abstracts and articles related to the topic and available online describe SSR as a complication of benign disorders (infections above all). In contrast 21 out of 41 patients had malignant disease in Görg et al. group ${ }^{2}$.

The immediate cause of SSR is not known. Patients deny any injury. However, it is impossible to exclude minimal trauma that was not noticed. It has no adverse conse- 
quence for a healthy human, but might become a serious complication in patient, suffering from some predisposition implies to SSR.

Injury in the splenic rupture setting was excluded in the anamnesis of our patients using repeated targeted questions. The importance of thrombocytopenia on SSR development in the first patient remains unclear.

We can also discuss the importance of spleen size at the time of rupture. Of course it is not the most important risk factor, because we quite often examine patients with significantly large splenomegaly in our work experience. The rate of spleen enlargement is apparently very important. This can be illustrated by both case reports - patients suffering from active underlying disease have the highest rate of tumour burden growth. On the other hand it is the only case of underlying disease with such a complication in two patients, although splenomegaly is common in patients with hairy cell leukemia and not rare in patients with diffuse large B-cell lymphoma.

The type of underlying disease is a significant prognostic factor in SSR - malignant disease is connected with high risk of early mortality ${ }^{2}$. The diagnosis is based on detailed obtaining of history, objective examination and on imaging and laboratory methods as well. Patients usually have a short history of stomach pain localized especially in the left hypochondrium. Acute pain occurs in the left shoulder at the same time frequently. It is a sign of irritation of the diaphragm (Kehr's sign). The pain is accompanied by rapidly worsening anaemia (without hemolysis marks), sometimes with progress to hypovolemic shock. Less common localization of the pain made the surgical consultant recommend an urgent gastrofibroscopy in the first patient.

All these symptoms indicate the SSR possibility, especially in patients with an underlying disease as mentioned above. It could be the first symptom of a serious disease as the second case report showed. The diagnosis of SSR is usually confirmed by imaging (ultrasonography or CT scan) or by laparotomy finding.

The treatment can be conservative or surgical, depending on the seriousness of the complication. The conservative treatment is preferred in less important situations without extensive bleeding. Accurate monitoring is necessity. Surgical treatment based on splenectomy is in general necessary in serious cases with hemoperitoneum and hypovolemic shock development. Subsequent histologic examination of spleen reveals the primary cause of SSR unless it was known from the anamnesis. The prognosis of patients depends on underlying disease, as primary cause of the complication and on an early assessment of diagnosis as well.
The risk of OPSI (overwhelming postsplenectomy infection) should be considered in patients after splenectomy and prophylactic measures are recommended (ATB prophylaxis and vaccination included).

\section{CONCLUSION}

Spontaneous splenic rupture should be considered in the differential diagnostics of painful splenomegaly and rapidly worsening anemia or hypovolemic shock even if the patient has no history of malignant disease.

The cases described above confirm that spontaneous splenic rupture can be the first sign of serious disease and/ or an unexpected complication of a chronic disorder.

\section{REFERENCES}

1. Knoblich R. Pathologic (so-called spontaneous) rupture of spleen in leukemia and lymphoma. Mich Med, 1966; 65:105-110.

2. Görg C, Cölle K, Görg K, Zugmaier G. Spontaneous rupture of the spleen: ultrasound patterns, diagnosis and follow-up. Brit J Radiol, 2003; 76:704-711.

3. Hoar FJ, Chan S-Y, Stonelake PS, Wolverson RW, Bareford D. Splenic rupture as a consequence of dual malignant pathology: a case report. J Clin Pathol, 2003; 56:709-710.

4. Sivelli R, Piccolo D, Soliani P, Franzini C, Ziegler S, Sianesi M. Rupture of the spleen in angiosarcoma: a case report and review of the literature. Chir Ital, 2005; 5:377-380.

5. Low SE, Stafford JS. Malignant histiocytosis: a case report of a rare tumour presenting spontaneous splenic rupture. J Clin Pathol, 2006; 59 (7):770-2.

6. Bouroncle BA. Unusual presentations and complications of hairy cell leukemia. Leukemia, 1987; 1(4):288-293.

7. Yam LT, Crosby WH. Spontaneous rupture of spleen in leukemic reticuloendotheliosis. Am J Surg, 1979; 137(2):270-273.

8. Gorgone S, Pratico C, Di Pietro N, Melita G, Sano M, De Luca $\mathrm{M}$, et al. Spontaneous splenic rupture in a patient with cytomegalovirus infection. G Chir, 2005; 26(3):95-99.

9. Gockel HR, Heidemann J, Lorenz D, Gockel I. Spontaneous splenic rupture, in tertian malaria. Infection, 2006; 34(1):43-45.

10. Carlisle P, Shiffman MM. Spontaneous splenic rupture in mononucleosis. Calif Med, 1957; 86(4):257-259.

11. Kim HJ, Lee GW, Park DJ, Lee JD, Chang SH. Spontaneous Splenic Rupture in a Hemodialysis Patient. Yonsei Med J, 2005; 46:435-438.

12. Kapan M, Kapan S, Karabicak I, Bavunoglu I. Simultaneous rupture of the liver and spleen in a patient on warfarin therapy: report of a case. Surg Today, 2005; 35(3):252-255.

13. Pazdirek F, Leffler J, Pipkova R. Spontaneous rupture of a splenic pseudocyst. Rozhl Chir, 2004; 83:128-130.

14. Nuamah NM, Goker H, Kilic YA, Dagmoura H, Cakmak A. Spontaneous splenic rupture in a healthy allogeneic donor of peripheral-blood stem cell following the administration of granulocyte colony-stimulating factor (G-CSF). A case report and review of the literature. Haematologica, 2006 May; 91 (5 Suppl):ECR08.

15. Dincer AP, Gottschall J, Margolis DA. Splenic rupture in a parental donor undergoing peripheral blood progenitor cell mobilization. J Pediatr Hematol Oncol, 2004; 26:761-763. 